\title{
A Novel Role for Brain Natriuretic Peptide: Inhibition of IL-1 $\beta$ Secretion via Downregulation of NF-kB/Erk 1/2 and NALP3/ASC/Caspase-1 Activation in Human THP-1 Monocyte
}

\author{
Letizia Mezzasoma, Cinzia Antognelli, and Vincenzo Nicola Talesa \\ Department of Experimental Medicine, University of Perugia, Piazzale L. Severi 1, 06129 Perugia, Italy \\ Correspondence should be addressed to Letizia Mezzasoma; letizia.mezzasoma@unipg.it
}

Received 8 September 2016; Revised 15 December 2016; Accepted 18 January 2017; Published 26 February 2017

Academic Editor: Hermann Gram

Copyright (C) 2017 Letizia Mezzasoma et al. This is an open access article distributed under the Creative Commons Attribution License, which permits unrestricted use, distribution, and reproduction in any medium, provided the original work is properly cited.

\begin{abstract}
Interleukin-1 $\beta$ (IL-1 $\beta$ ) is a pleiotropic cytokine and a crucial mediator of inflammatory and immune responses. IL- $1 \beta$ processing and release are tightly controlled by complex pathways such as NF-kB/ERK1/2, to produce pro-IL-1 $\beta$, and NALP3/ASC/Caspase1 inflammasome, to produce the active secreted protein. Dysregulation of both IL- $1 \beta$ and its related pathways is involved in inflammatory/autoimmune disorders and in a wide range of other diseases. Identifying molecules modulating their expression is a crucial need to develop new therapeutic agents. IL- $1 \beta$ is a strong regulator of Brain Natriuretic Peptide (BNP), a hormone involved in cardiovascular homeostasis by guanylyl cyclase Natriuretic Peptide Receptor (NPR-1). An emerging role of BNP in inflammation and immunity, although proposed, remains largely unexplored. Here, we newly demonstrated that, in human THP-1 monocytes, LPS/ATP-induced IL-1 $\beta$ secretion is strongly inhibited by BNP/NPR-1/cGMP axis at all the molecular mechanisms that tightly control its production and release, NF-kB, ERK 1/2, and all the elements of NALP3/ASC/Caspase-1 inflammasome cascade, and that NALP3 inflammasome inhibition is directly related to BNP deregulatory effect on NF-kB/ERK $1 / 2$ activation. Our findings reveal a novel potent anti-inflammatory and immunomodulatory role for BNP and open new alleys of investigation for a possible employment of this endogenous agent in the treatment of inflammatory/immune-related and IL- $1 \beta / \mathrm{NF}-$ kB/ERK1/2/NALP3/ASC/Caspase-1-associated diseases.
\end{abstract}

\section{Introduction}

IL-1 $\beta$, released by activated monocytes and macrophages, is a critical player in proinflammatory pathways activation in nearly every tissue and organ [1-3]. In particular, IL-1 $\beta$ is implicated in both acute and chronic inflammation and in cell growth, differentiation, angiogenesis, profibrogenic mediators production, immune response regulation, and carcinogenesis [1-11]. A fine-tune control of its secretion is required and achieved by a two-steps mechanism acting both at transcriptional and at posttranslational level. Firstly, the inactive cytoplasmic precursor (pro-IL-1 $\beta$ ) is synthesized; subsequently the active protein is produced by Caspase1 proteolytic cleavage of the precursor and released into the extracellular space where it initiates its wide range of responses $[1-5,12]$. The first step of the mechanism requires the activation of specific complex pathways, such as nuclear factor-kB (NF-kB) and extracellular-signal regulated kinases $1 / 2$ (ERK 1/2) $[4,6,13]$. The second step requires the activation of molecular platforms called inflammasomes, inducing the activation of the proteolytic enzyme Caspase-1. Inflammasomes are composed of nucleotide-binding domain leucine-rich repeat (NLR) receptors, adaptor proteins, and the effector protein pro-Caspase-1 [1-6]. The most extensively studied inflammasome is NLRP3/NALP3, formed by the NLR pyrin domain containing 3 (NLRP3, also known as NALP3 or cryopyrin) receptors and by the apoptosis-associated specklike protein containing a Caspase activation and recruitment domain (ASC) adapter [1-6]. NALP3 inflammasome activation, induced by a large variety of endogenous and exogenous stimuli, appears to occur in two steps. The first one, priming/licensing step, leads to the activation of 
NF-KB-mediated signaling, which in turn upregulates transcription of inflammasome-related components, including inactive NALP3 and pro-IL-1 $\beta$. The second one is the oligomerization of NALP3 and subsequent assembly of NALP3/ASC/pro-Caspase-1 to a complex triggering the activation of pro-Caspase- 1 in Caspase- 1 active fragment, as well as the production and secretion of mature IL- $1 \beta$. Once activated, NALP3 represents a major player in innate immune host defense [2-4, 6, 14].

As known, NF-kB and ERK 1/2 pathways play a crucial role in a wide range of processes such as inflammation, stress response, apoptosis, cell survival, proliferation, angiogenesis, and innate and acquired immunity. In addition, their dysregulation is involved in a variety of diseases, including autoimmune, neurodegenerative, and inflammatory disorders, and in cancer [15-18]. Likewise, inappropriate activation of IL- $1 \beta$ and NALP3 is a common feature of a wide range of major human diseases, such as gout [19], type 2 diabetes [20], obesity-induced insulin resistance [21], Crohn's diseases [22], silicosis [23], psoriasis [10], cancer [4, 24], atherosclerosis [8], and Alzheimer's disease [25], known to affect millions of people worldwide. Finally, ASC itself is also involved in inflammasome-independent cascade: Caspase-1 independent activation of necrosis [26], antigens-induced arthritis [27], apoptosis in tumor cell lines [28], and regulation of inflammatory cytokines production, by NF-kB and MAPK pathways activation $[2,28]$. Hence, the extensive involvement of IL-1 $\beta$, NF-kB, ERK 1/2, NALP3, ASC and Caspase- 1 in such a range of diseases makes them high desirable drug targets.

IL- $1 \beta$ is a strong regulator of Brain Natriuretic Peptide BNP (BNP) [29], a member of the Natriuretic Peptides (NPs) family, synthetized and secreted constitutively by the heart, deeply involved in body fluid and cardiovascular homeostasis [30, 31]. BNP is upregulated in myocardium in response to many pathophysiological stimuli and exerts its biological functions by guanylyl cyclase Natriuretic Peptide Receptor-1 (NPR-1/NPR-A) [30-34]. NPR-1 activation induces an increase of cGMP intracellular levels, leading to the activation of specific cGMP-dependent protein kinases, phosphodiesterases and cyclic nucleotide gated cation channels [30, 31, 34]. NPs and NPR-1 are expressed in many tissues and exert endocrine, autocrine, and paracrine effects in normal or pathological conditions $[30,31,34]$ and a wide range of further activities, including an emerging role on inflammation and immunity [30, 31, 35-38]. In particular, BNP plasma level is upregulated in patients during inflammatory contexts, such as sepsis or septic shock $[37,39]$ and in several inflammatory diseases with or without cardiac dysfunction [37]. In addition, the main cytokines released during inflammation increase BNP production and secretion in vitro $[37,40,41]$ and in many conditions where IL-1 $\beta$ and other cytokines levels are increased [42], BNP plasma levels may be particularly elevated [43]. Finally, BNP inhibits monocytes chemotaxis [35] and influences some inflammatory mediators production in macrophages [36] and NPR-1 is expressed on immune cells [30, 35, 38, 44, 45]. Altogether, these observations suggest a role for BNP in inflammation and its possible immunomodulatory action. However, the relationship between $\mathrm{BNP} /$ inflammation/immune systems still remains to be widely investigated. In addition, despite BNP modulates some proinflammatory cytokines production [36], no data exist about its effect on human IL-1 $\beta$ secretion.

The aim of our study was to evaluate BNP effect on IL- $1 \beta$ release and NF-kB, ERK 1/2, NALP3, ASC, and Caspase-1 activation in LPS/ATP stimulated human THP1 monocytes. For the first time to our knowledge, we demonstrated that BNP/NPR-1/cGMP axis strongly downregulated IL-1 $\beta$ secretion from THP-1 monocytes by inhibiting NF-kB and ERK $1 / 2$ activation and all the elements of NALP3 inflammasome cascade. Analyzing the mechanism of action of BNP-dependent NALP3 inflammasome inhibition, we demonstrated that it is directly related to BNP deregulatory effect on NF-kB/ERK 1/2 activation. Our data, demonstrating such multiple inhibitory actions of BNP, reveal a novel potent anti-inflammatory and immunomodulatory role for this peptide. In addition, our study suggests that BNP might be a promising therapeutic agent for the treatment of inflammatory/immune-related and IL- $1 \beta / \mathrm{NF}$ $\mathrm{kB} / \mathrm{ERK} 1 / 2 / \mathrm{NALP} 3 / \mathrm{ASC} / \mathrm{Caspase}$-1-associated diseases and, in general, in those pathophysiological scenarios where inflammatory and immune networks are involved.

\section{Materials and Methods}

2.1. Reagents. All the chemicals used in the present study were analytical grade reagents from various sources. Human BNP was obtained from Phoenix Europe GmbH (Germany) and dissolved in $\mathrm{H}_{2} \mathrm{O}$. LPS, ATP, and Phorbol 12-myristate 13-acetate (PMA) were purchased from Sigma-Aldrich (Italy) and dissolved in RPMI, $\mathrm{H}_{2} \mathrm{O}$ and DMSO, respectively. The NF-kB and ERK 1/2 inhibitors, BAY 11-7082, and U0-126, respectively, were obtained from Santa Cruz Biotechnology, Inc. (Germany) and dissolved in 0.5\% DMSO. NALP3 mouse monoclonal antibody $(\mathrm{mAb})$ was from Adipogen International (USA). Caspase-1 rabbit polyclonal antibody (pAb), Phospho-IkB- $\alpha$ (Ser32) rabbit mAb, Phospho-p44/42 MAPK (ERK 1/2) (Thr202/Tyr204) rabbit pAb, IL-1 $\beta$ mouse mAb, and the appropriate HRP-conjugated secondary Abs were from Cell Signaling Technology (USA). NPR-1 rabbit pAb and $\beta$-actin mouse $\mathrm{mAb}$ were from Santa Cruz Biotecnology, Inc. (Germany). ASC rabbit pAb was from Enzo Life Sciences (USA).

2.2. Cell Culture and Drug Treatments. Human THP-1 monocytes were purchased from American Type Culture Collection (ATCC, USA) and routinely maintained at $37^{\circ} \mathrm{C}$ in $5 \%$ $\mathrm{CO}_{2}$ in RPMI 1640 supplemented with $10 \%$ heat inactivated $\left(1 \mathrm{~h}\right.$ at $\left.56^{\circ} \mathrm{C}\right) \mathrm{FBS}, 1 \mathrm{x}$ L-glutamine, $1 \mathrm{mM}$ sodium pyruvate, $1 \mathrm{x}$ nonessential amino acids, 100 units $/ \mathrm{mL}$ of penicillin, and $0.1 \mathrm{mg} / \mathrm{mL}$ of streptomycin (Invitrogen, Italy). THP-1 cells were plated $\left(2 \times 10^{6}\right.$ cells/well $)$ in $35 \mathrm{~mm}$ six-well culture dishes and treated for $30 \mathrm{~min}$ or 24,48 , and $72 \mathrm{~h}$ with $10 \mu \mathrm{g} / \mathrm{mL}$ LPS $/ 5 \mathrm{mM}$ ATP in the presence or absence of $10^{-6}$ and $10^{-8} \mathrm{M}$ human BNP. In independent experiments, $10 \mu \mathrm{M}$ BAY 11-7082 or U0-126 were added to cells $1 \mathrm{~h}$ before LPS/ATP treatment. In independent experiments, THP-1 cells were differentiated to macrophage-like cells by $20 \mathrm{nM}$ 
PMA for $72 \mathrm{~h}$, washed three times with PBS, and plated $\left(2 \times 10^{6}\right.$ cells/well $)$ in $35 \mathrm{~mm}$ six-well culture dishes and, after $24 \mathrm{~h}$, treated for $30 \mathrm{~min}$ with $10 \mu \mathrm{g} / \mathrm{mL}$ LPS/5 mM ATP in the presence or absence of $10^{-8} \mathrm{M}$ human BNP. DMSO was used at $0.0005 \%$ assay concentration producing no significant toxicity. Control cells with DMSO did not show any significant difference with respect to control cells in RPMI 1640 medium; therefore all the relative treatments were compared to these latter controls.

2.3. Cell Viability. Cell viability was measured with a standard trypan blue uptake assay. Cell cultures were also morphologically examined via light microscopy.

2.4. Measurements of Secreted IL-1 $\beta$. Measurements of secreted IL-1 $\beta$ were performed in $100 \mu \mathrm{L}$ supernatant after THP1 exposure to the indicated compounds for 24,48 , and $72 \mathrm{~h}$ at $37^{\circ} \mathrm{C}$. After treatments, supernatants were collected and human IL-1 $\beta$ levels were determined by the specific ELISA kit, according to the manufacturer's guidelines (eBioscience, USA).

2.5. cGMP Measurements. cGMP intracellular levels were determined by the specific EIA kit, according to the manufacturer's guidelines (GE Healthcare, UK). THP-1 cells were plated $\left(1 \times 10^{6}\right.$ cells/well $)$ in 48 -well culture dishes, incubated for 5 and $30 \mathrm{~min}$ with $10^{-8} \mathrm{M}$ human BNP, in absence or presence of $10 \mathrm{ug} / \mathrm{mL}$ LPS/5 mM ATP, and lysed in $200 \mu \mathrm{L}$ of the provided lysis buffer. Measurements were performed in $50 \mu \mathrm{L}$ of the lysate.

2.6. Western Blot Analysis. Total proteins $(20 \mu \mathrm{g})$ were separated by $12 \%$ sodium dodecyl sulfate-polyacrylamide gel electrophoresis (SDS-PAGE) and blotted onto a nitrocellulose membrane, using iBlot Dry Blotting System (Invitrogen, Italy). Nonspecific binding sites were blocked in Roti-Block (Roth $\mathrm{GmbH}$, Germany) for $1 \mathrm{~h}$ at room temperature. The membranes were blotted overnight at $4^{\circ} \mathrm{C}$ with Roti-Block containing the following anti-human Abs:NPR-1 (1:200 dilution), ASC $(1 \mu \mathrm{g} / \mathrm{mL})$, NALP3, Caspase-1, PhosphoIkB- $\alpha$, Phospho-p44/42 MAPK, and IL-1 $\beta$ (1:1000 dilution). After washing with TBST, antigen-Ab complexes were detected by incubation for $1 \mathrm{~h}$ at room temperature with the appropriated HRP-conjugated secondary Abs (1:2000 dilution) and revealed using the enhanced chemiluminescence (ECL) system by Amersham Pharmacia, Biotech (Sweden). As internal loading controls and for normalizing purpose, all membranes were stripped of the first antibody and reprobed with anti- $\beta$-actin Ab (1:1000 dilution). Densitometry analyses were performed with ImageJ software.

2.7. Statistical Analysis. Results were expressed as means \pm $\mathrm{SD}$ of three independent experiments performed in triplicate. The statistical significance of differences between treated and untreated cells was assessed by Student's $t$-test. Differences between groups were considered significant when $P<0.05$.

\section{Results}

3.1. BNP Decreases LPS/ATP-Induced IL-1 $\beta$ Release in THP-1 Cells. We firstly evaluated the effect of $10^{-6}$ and $10^{-8} \mathrm{M}$ BNP on LPS/ATP-induced IL- $1 \beta$ release in THP-1 culture medium after 24 (Figure 1(a)), 48 (Figure 1(b)) and $72 \mathrm{~h}$ (Figure 1(c)) cotreatment. We demonstrated that BNP inhibited LPS/ATPinduced IL- $1 \beta$ secretion at all doses and exposure times, the effect obtained being already at $10^{-8} \mathrm{M}$ after $48 \mathrm{~h}$ treatment. BNP did not affect cell viability at any concentrations used (Figures 1(d), 1(e), and 1(f)). On the contrary, LPS/ATP treatment induced a marked cell death at all the exposure times (Figures 1(d), 1(e), and 1(f)), thus suggesting an intense NALP3 inflammasome activation.

3.2. BNP Activates NPR-1 in THP-1 Cells. BNP promotes its biological effects binding to NPR-1 [30, 31, 34] that, once activated, induces an increase in cGMP intracellular levels. We showed that $10^{-8} \mathrm{M}$ BNP treatment produced a significant increase in cGMP intracellular levels, either after $5 \mathrm{~min}$ or $30 \mathrm{~min}$ exposure (Figure 2(a)), without affecting NPR-1 protein expression (Figure 2(b)), thus indicating BNP/NPR$1 /$ cGMP pathway activation.

3.3. BNP Is Involved in the Priming Mechanism Controlling $I L-1 \beta$ Production by Inhibiting NF- $k B$ and ERK $1 / 2$ Activation in THP-1 Cells. IL-1 $\beta$ secretion is tightly controlled by two signals, one inducing the upregulation of the intracellular pro-IL-1 $\beta$ and the other one driving the secretion of the active molecule. LPS/ATP-induced inflammatory mediators production being predominantly regulated by NF-kB and ERK1/2 signaling $[6,15,46]$, we firstly demonstrated the effective involvement of these pathways in our system by using the specific NF-kB and ERK 1/2 inhibitors BAY 117082 and U0-126, respectively. In fact, $10 \mu \mathrm{M}$ BAY 11-7082 or U0-126 $1 \mathrm{~h}$ pretreatment reduced $48 \mathrm{~h}$ LPS/ATP-induced IL$1 \beta$ release (Figure $3(\mathrm{a})$ ). We then demonstrated that $10^{-8} \mathrm{M}$ BNP treatment abrogated and downregulated LPS/ATPinduced NF-kB and ERK 1/2 activation, respectively (Figures 3 (b) and 3(c)), as indicated by the decrease of serine 32phosphorylated IkB- $\alpha$ (Figure 3(b)) and total phosphorylated ERK 1/2 protein levels (Figure 3(c)), either after $30 \mathrm{~min}$ or $48 \mathrm{~h}$. We then showed that $10^{-8} \mathrm{M}$ BNP treatment downregulated LPS/ATP-induced pro-IL-1 $\beta$ protein expression after $48 \mathrm{~h}$ (Figure 3(d)) exposure. Finally, we demonstrated NF-kB and ERK $1 / 2$ involvement also in pro-IL- $1 \beta$ protein expression, finding that $10 \mu \mathrm{M}$ BAY 11-7082 (Figure 3(e)) and U0126 (Figure 3(f)) pretreatment downregulated and reverted LPS/ATP-induced pro-IL-1 $\beta$ expression, respectively, after $48 \mathrm{~h}$ exposure. Altogether, these data demonstrated that BNP strongly inhibits the priming mechanism controlling IL- $1 \beta$ production by downregulating NF-kB and ERK/1/2 activation, both involved in pro- and mature IL- $1 \beta$ production.

3.4. BNP Is Involved in the Second Mechanism Controlling IL$1 \beta$ Production by Inhibiting NALP3, ASC, and Caspase-1 Cascade Activation in THP-1 Cells. To evaluate BNP involvement also in the second signal driving the secretion of the active IL-1 $\beta$, we investigated BNP effect on NALP3 cascade, the 


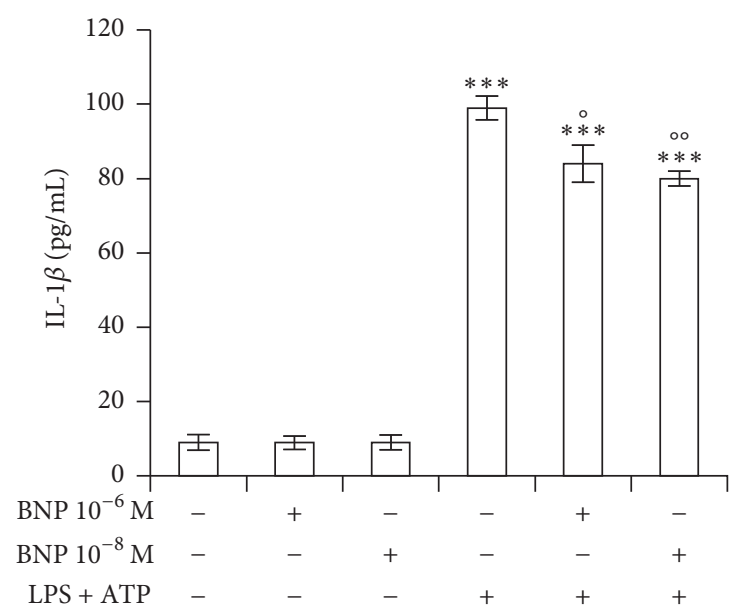

(a)

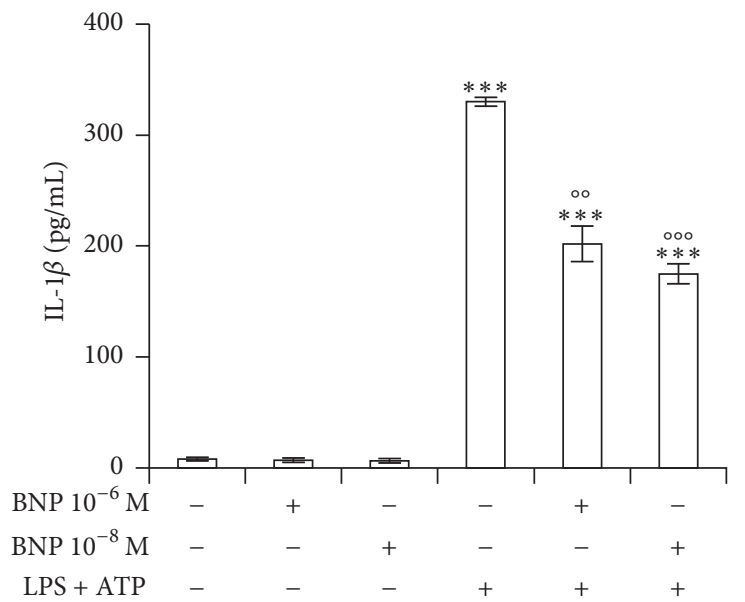

(b)

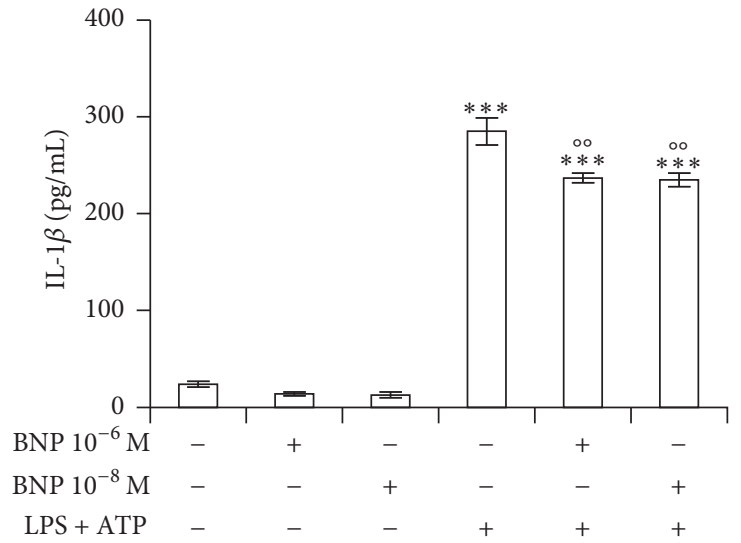

(c)

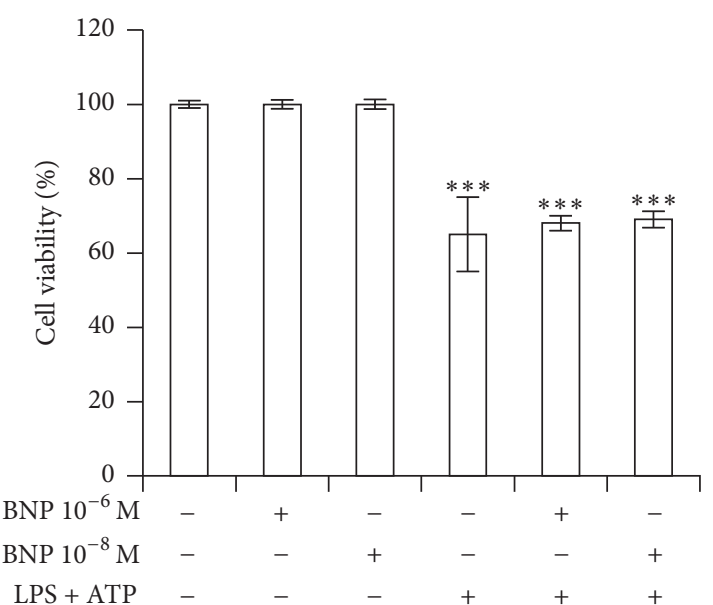

(d)

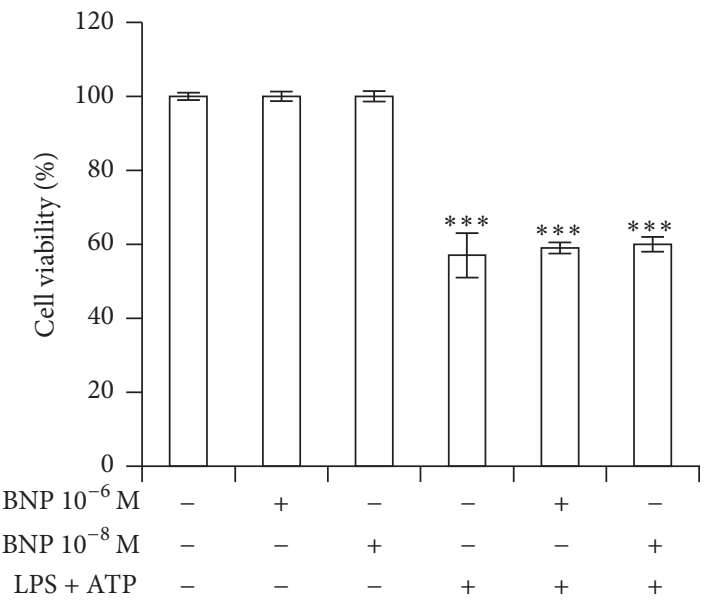

(e)

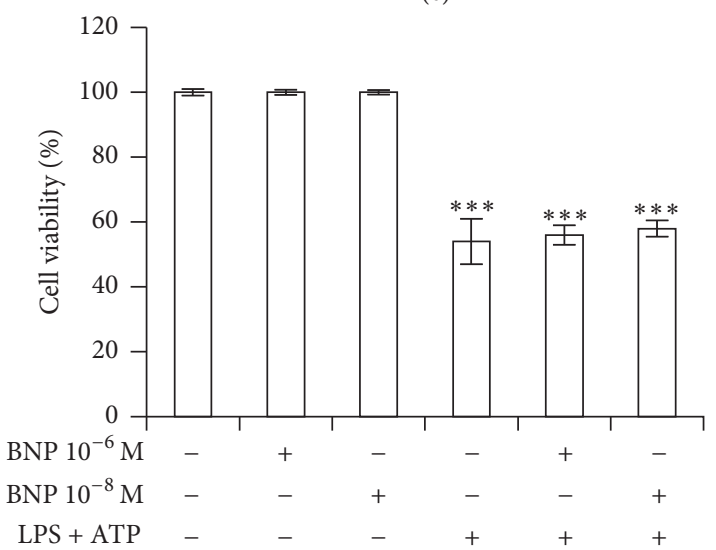

(f)

Figure 1: BNP decreases LPS/ATP-induced IL-1 $\beta$ release in THP-1 cells. THP-1 cells were treated with $10^{-6}$ and $10^{-8} \mathrm{M} \mathrm{BNP}$ in absence or presence of $10 \mu \mathrm{g} / \mathrm{mL} \mathrm{LPS} / 5 \mathrm{mM}$ ATP for $24(\mathrm{a}, \mathrm{d}), 48(\mathrm{~b}, \mathrm{e})$, and $72 \mathrm{~h}(\mathrm{c}, \mathrm{f})$. The supernatants were collected and IL-1 $\beta$ release was measured by ELISA $(a, b, c)$. Cell viability was assessed by trypan blue uptake assay $(d, e, f)$. Histograms indicate means \pm SD of three separate experiments each one tested in triplicate. ${ }^{* * *} P<0.001$ versus untreated cells and ${ }^{\circ} P<0.05,{ }^{\circ} P<0.01$, and ${ }^{\circ 00} P<0.001$ versus LPS/ATP treated cells.

molecular platform whose activation triggers the maturation of Caspase-1, resulting in IL-1 $\beta$ production $[1-4,12]$. We demonstrated that $10^{-8} \mathrm{M}$ BNP treatment abrogated $30 \mathrm{~min}$ LPS/ATP-induced NALP3 protein expression (Figure 4(a)), downregulated ASC protein expression, both at basal or after LPS/ATP stimulation (Figure 4(b)), and abrogated Caspase1 activation, both at basal or after LPS/ATP stimulation, as indicated by the downregulation of the p20 active Caspase-1 


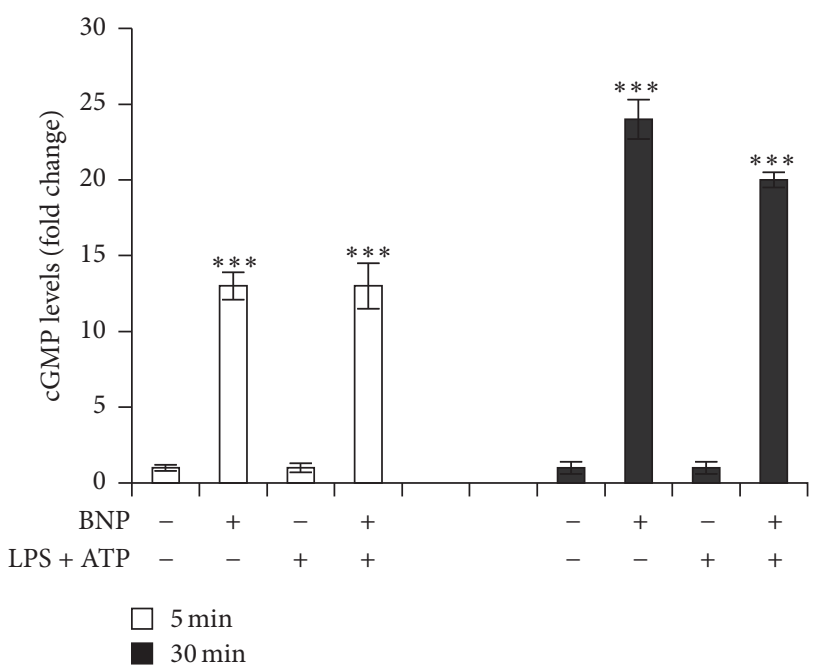

(a)

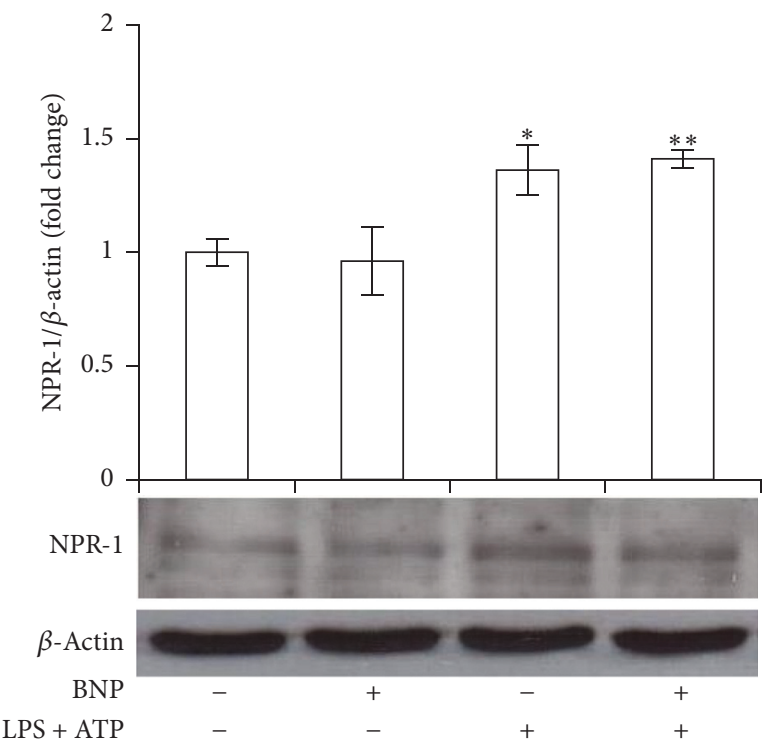

(b)

Figure 2: BNP activates NPR-1 in THP-1 cells. (a) THP-1 cells were treated with $10^{-8} \mathrm{M}$ BNP in absence or presence of $10 \mu \mathrm{g} / \mathrm{mL} \mathrm{LPS} / 5 \mathrm{mM}$ ATP and cGMP intracellular levels were evaluated after 5 and 30 min treatment. (b) THP- 1 cells were treated with $10^{-8} \mathrm{M}$ BNP in absence or presence of $10 \mu \mathrm{g} / \mathrm{mL}$ LPS $/ 5 \mathrm{mM}$ ATP for $30 \mathrm{~min}$. Cell lysates were immunoblotted for NPR-1. The blots were stripped of the bound Ab and reprobed with mouse anti- $\beta$-actin, to confirm equal loading. Western blots are representative of three separate experiments. Histograms indicate means $\pm \mathrm{SD}$ of three separate experiments each one tested in triplicate. ${ }^{*} P<0.05,{ }^{* *} P<0.01$, and ${ }^{* * *} P<0.001$ versus untreated cells.

fragment (Figure 4(c)). Altogether these results demonstrate BNP inhibitory action on the second part of the mechanism controlling IL- $1 \beta$ production.

\subsection{NF- $k B$ and ERK 1/2 Are Involved in NALP3/ASC/Caspase-} 1 Cascade Activation in THP-1 Cells. Both NF-kB and ERK $1 / 2$ can be involved in NALP3 and Caspase- 1 activation [4, $6,46]$. We then demonstrated the effective involvement of these pathways in our system, using the specific inhibitors BAY 11-7082 and U0-126. Ten $\mu$ M BAY 11-7082 or U0-126 $1 \mathrm{~h}$ pretreatment, indeed, abrogated $30 \mathrm{~min}$ LPS/ATP-induced NALP3 (Figures 5(a) and 5(d)) or ASC (Figures 5(b) and 5(e)) expression and Caspase-1 activation (Figures 5(c) and 5(f)), showing the effective involvement of both pathways in all the elements of NALP/ASC/Caspase-1 cascade.

3.6. BNP Is Involved in All the Molecular Mechanisms Controlling IL-1 $\beta$ Production and Release by Inhibiting the Activation of NF-kB, ERK 1/2, and NALP3/ASC/Caspase-1 Cascade in Macrophage-Like Cells. BNP effect on the molecular mechanisms controlling IL- $1 \beta$ production and release was finally evaluated also in macrophages. By using PMA differentiated THP-1 cells, we demonstrated that $10^{-8} \mathrm{M}$ BNP treatment abrogated and downregulated $30 \mathrm{~min}$ LPS/ATP-induced NF-kB and ERK 1/2 activation, respectively (Figure 6(a)). Regarding BNP effect on NALP3 cascade, we demonstrated that $10^{-8} \mathrm{M}$ BNP treatment abrogated $30 \mathrm{~min}$ LPS/ATPinduced NALP3 protein expression and Caspase-1 activation and downregulated ASC protein expression, respectively (Figure 6(b)). Altogether these results demonstrate BNP inhibitory action on all the steps of the mechanism controlling IL- $1 \beta$ production and secretion also in macrophage-like cells.

\section{Discussion}

IL- $1 \beta$ is a central mediator in inflammation and immunity. IL- $1 \beta$ production and release are tightly regulated by the activation of complex pathways such as NF-kB and ERK1/2, to induce pro-IL-1 $\beta$ upregulation, and NALP3/ASC/Caspase-1, to cleave pro-IL-1 $\beta$ into the biologically active secreted protein $[4,6,12,13,46]$. Considering the pathogenic roles of IL$1 \beta, \mathrm{NF}-\mathrm{kB}, \mathrm{ERK} 1 / 2$, and NALP3 inflammasome inappropriate activation in a large number of major human disorders and in cancer [1,2,4-11, 15-28], a large interest is focused on the identification of molecules able to target them, in order to develop new therapeutic agents. IL- $1 \beta$ is a potent regulator of BNP [29], a hormone/paracrine/autocrine factor mainly involved in body fluid and cardiovascular homeostasis, via the guanylyl cyclase NPR-1 [30, 31, 34]. An emerging role for BNP in inflammation and immune system has been suggested, even though it remains largely unexplored. Here, we newly demonstrated that, in human THP-1 monocytes, LPS/ATP-induced IL-1 $\beta$ secretion is strongly inhibited by BNP/NPR-1/cGMP axis, at all the molecular mechanisms that tightly control its production and release: NF-kB, ERK $1 / 2$ and all the elements of NALP3/ASC/Caspase-1 cascade (Figure 7). Due to the pivotal role of IL- $1 \beta$ on inflammation and immunomodulation, finding that an endogenous molecule, such as BNP, is able to strongly downregulate its release 


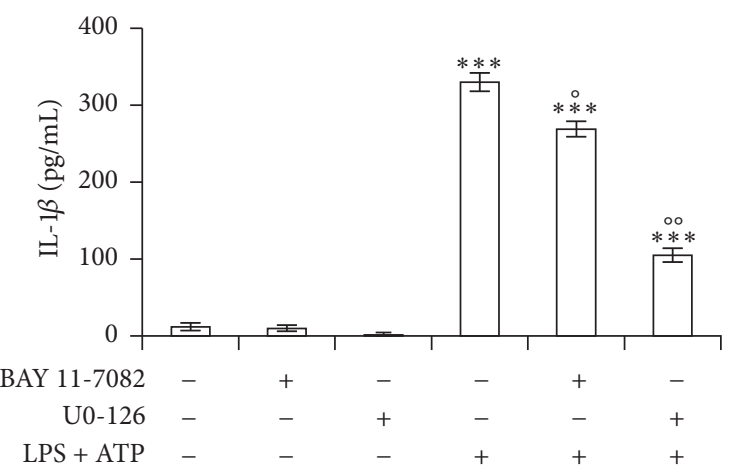

(a)

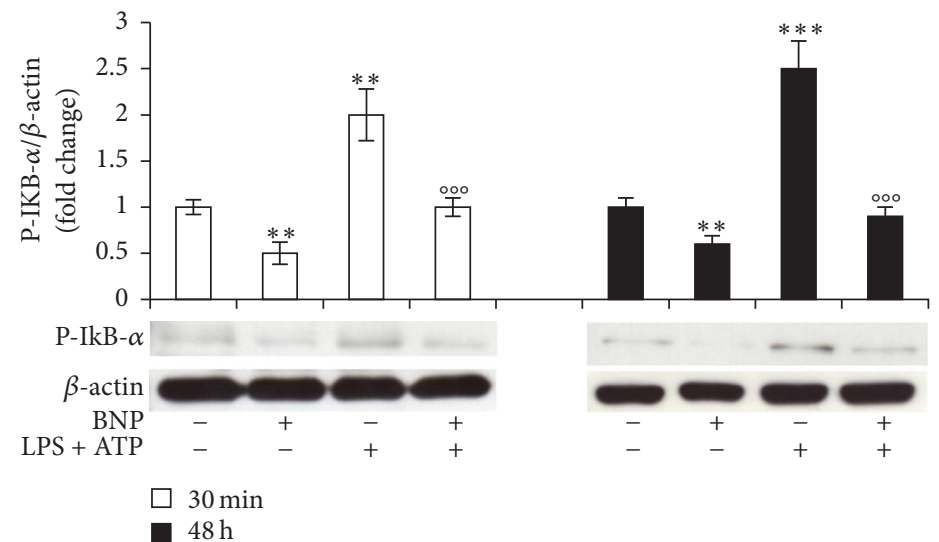

(b)

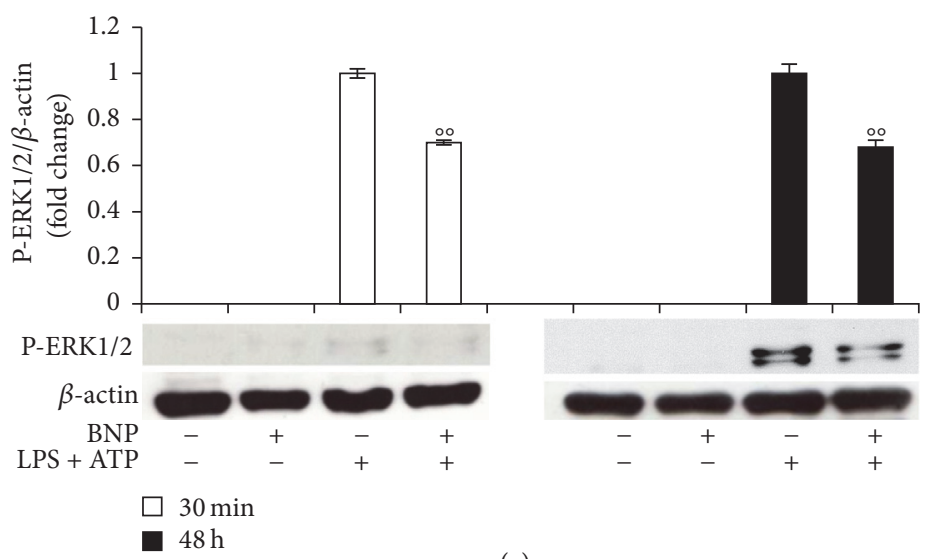

(c)

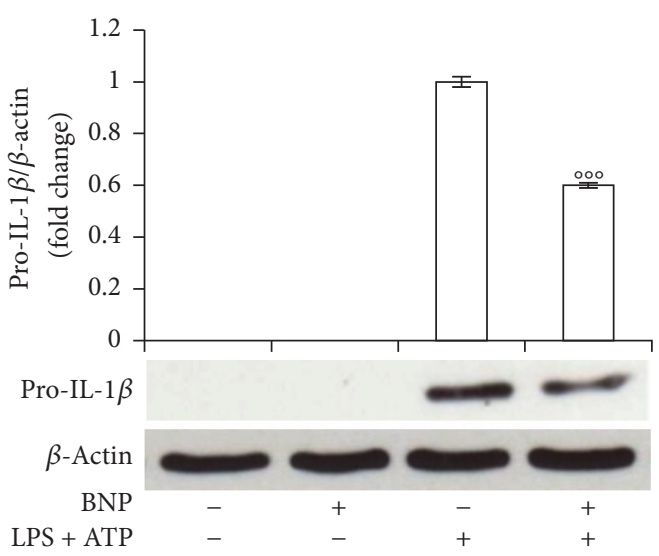

(d)
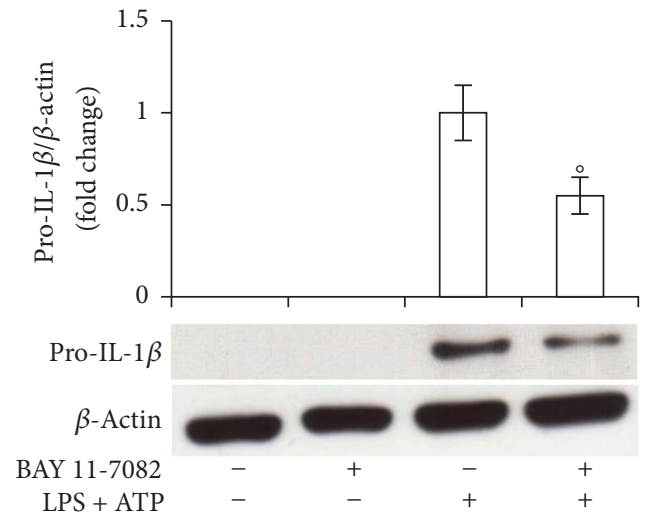

(e)

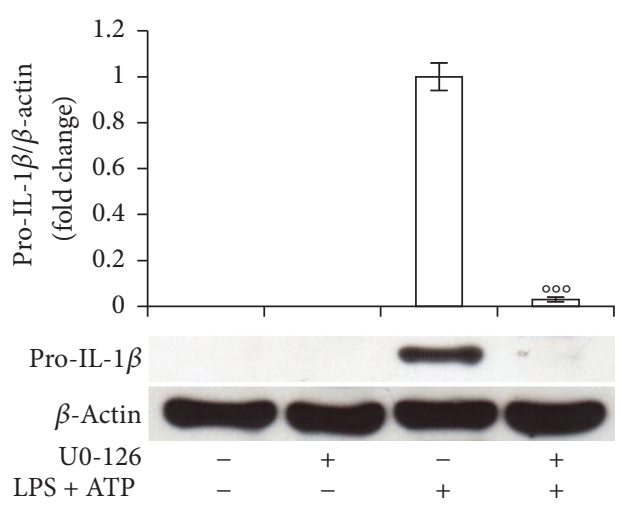

(f)

FIGURE 3: BNP is involved in the priming mechanism controlling IL- $1 \beta$ production by inhibiting NF-kB and ERK $1 / 2$ activation in THP-1 cells. (a) THP-1 cells were incubated with $10 \mu \mathrm{M}$ BAY $11-7082$ or U0-126 for $1 \mathrm{~h}$ and then treated with $10 \mu \mathrm{g} / \mathrm{mL} \mathrm{LPS} / 5 \mathrm{mM}$ ATP for $48 \mathrm{~h}$. The supernatants were collected and IL- $1 \beta$ release was measured by ELISA. (b, c, d) THP-1 cells were treated with $10^{-8} \mathrm{M}$ BNP in absence or presence of $10 \mu \mathrm{g} / \mathrm{mL}$ LPS $/ 5 \mathrm{mM}$ ATP for $30 \mathrm{~min}(\mathrm{~b}, \mathrm{c})$ or $48 \mathrm{~h} \mathrm{(b,} \mathrm{c,} \mathrm{d).} \mathrm{Cell} \mathrm{lysates} \mathrm{were} \mathrm{immunoblotted} \mathrm{for} \mathrm{P-IkB-} \alpha$ (b), P-ERK 1/2 (c), or pro-IL-1 $\beta$ (d). (e, f) THP-1 cells were incubated with $10 \mu \mathrm{M}$ BAY 11-7082 (e) or U0-126 (f) for $1 \mathrm{~h}$ and then treated with $10 \mu \mathrm{g} / \mathrm{mL} \mathrm{LPS} / 5 \mathrm{mM}$ ATP for $48 \mathrm{~h}$. Cell lysates were immunoblotted for pro-IL-1 $\beta$. The blots were stripped of the bound Ab and reprobed with mouse anti- $\beta$-actin, to confirm equal loading. Western blots are representative of three separate experiments. All histograms indicate means \pm SD of three separate experiments each one tested in triplicate. ${ }^{* *} P<0.01$ and ${ }^{* * *} P<0.001$ versus untreated cells and ${ }^{\circ} P<0.05,{ }^{\circ 0} P<0.01$, and ${ }^{\circ 00} P<0.001$ versus LPS/ATP treated cells. 


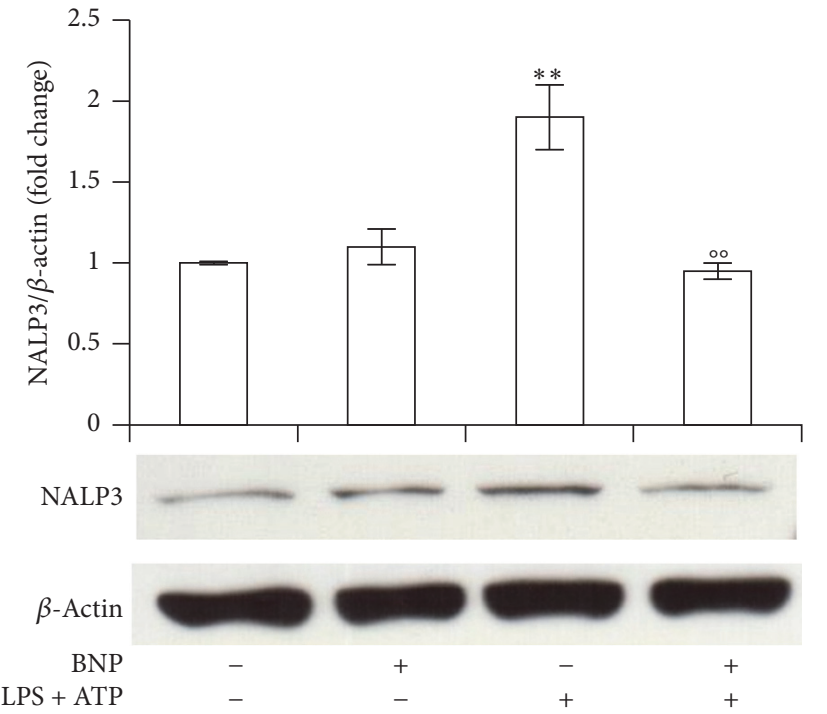

(a)

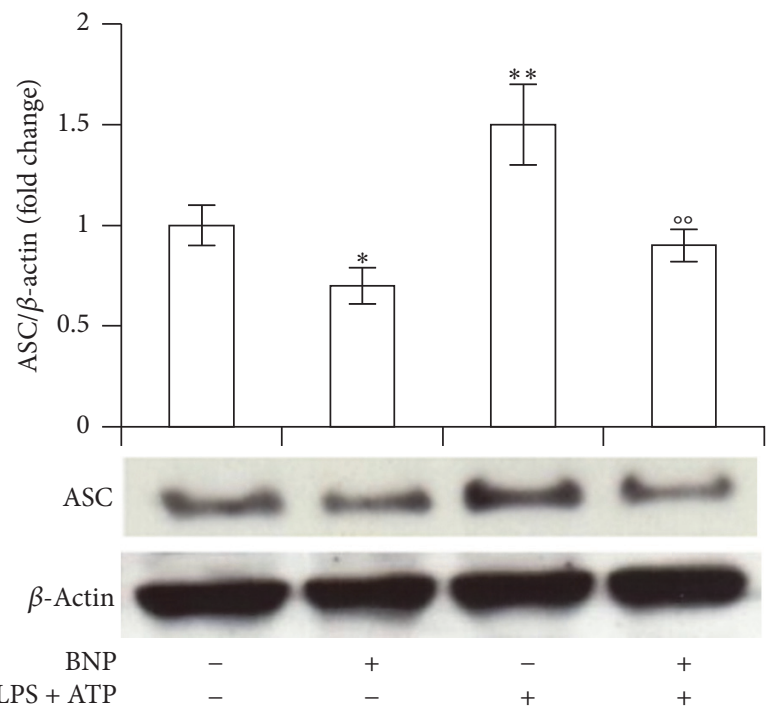

(b)

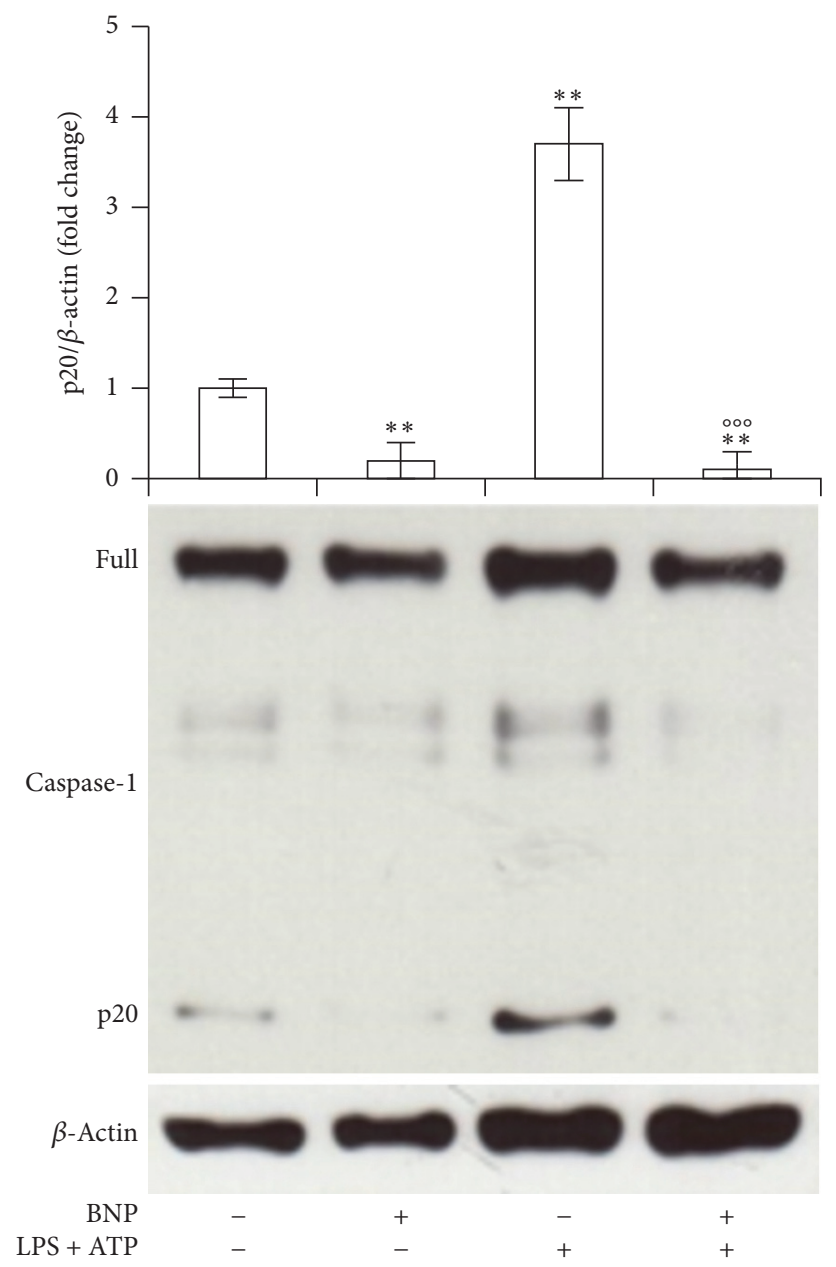

(c)

FIgURE 4: BNP is involved in the second mechanism controlling IL-1 $\beta$ production by inhibiting NALP3, ASC, and Caspase-1 cascade activation in THP-1 cells. THP-1 cells were treated with $10^{-8} \mathrm{M}$ BNP in absence or presence of $10 \mu \mathrm{g} / \mathrm{mL}$ LPS $/ 5 \mathrm{mM}$ ATP for $30 \mathrm{~min}$. Cell lysates were immunoblotted for NALP3 (a), ASC (b), or Caspase-1 (c). The blots were stripped of the bound Ab and reprobed with mouse anti- $\beta$-actin, to confirm equal loading. Western blots are representative of three separate experiments. Histograms indicate means \pm SD of three separate experiments each one tested in triplicate. ${ }^{*} P<0.05$ and ${ }^{* *} P<0.01$ versus untreated cells and ${ }^{\circ 0} P<0.01$ and ${ }^{\circ 00} P<0.001$ versus LPS/ATP treated cells. 


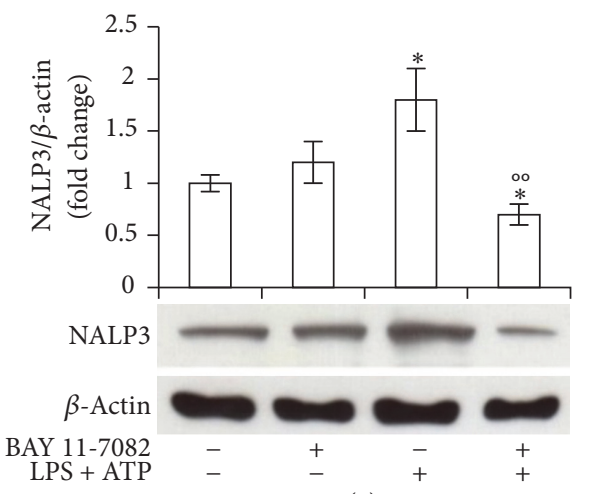

(a)

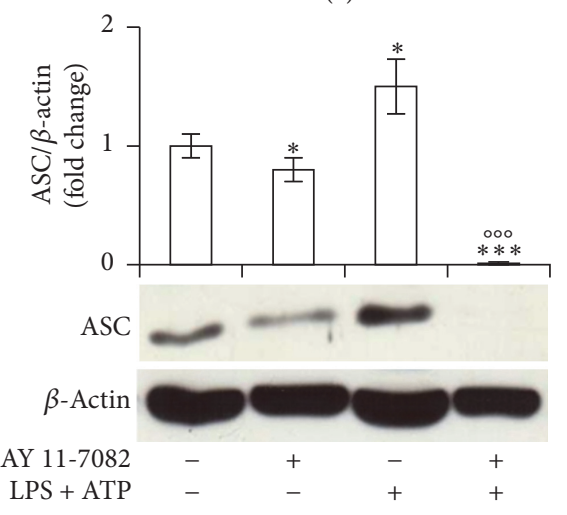

(b)

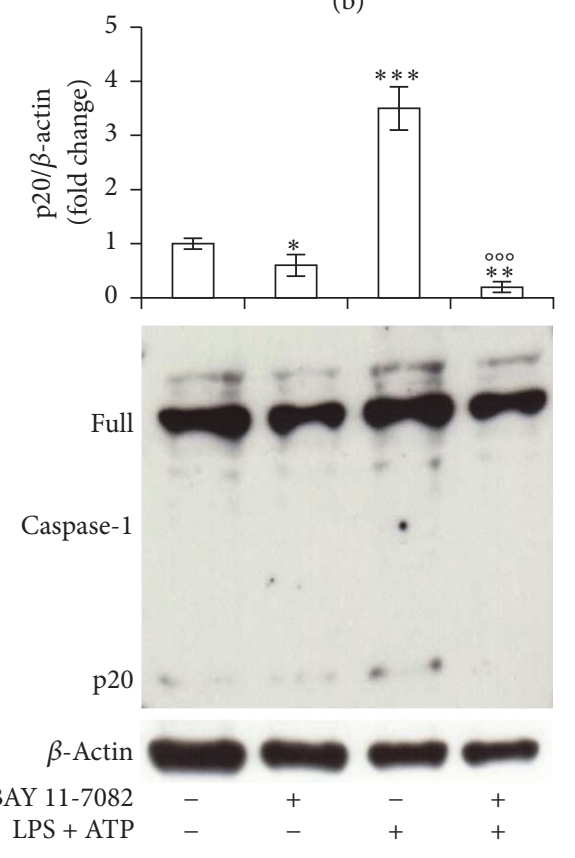

(c)
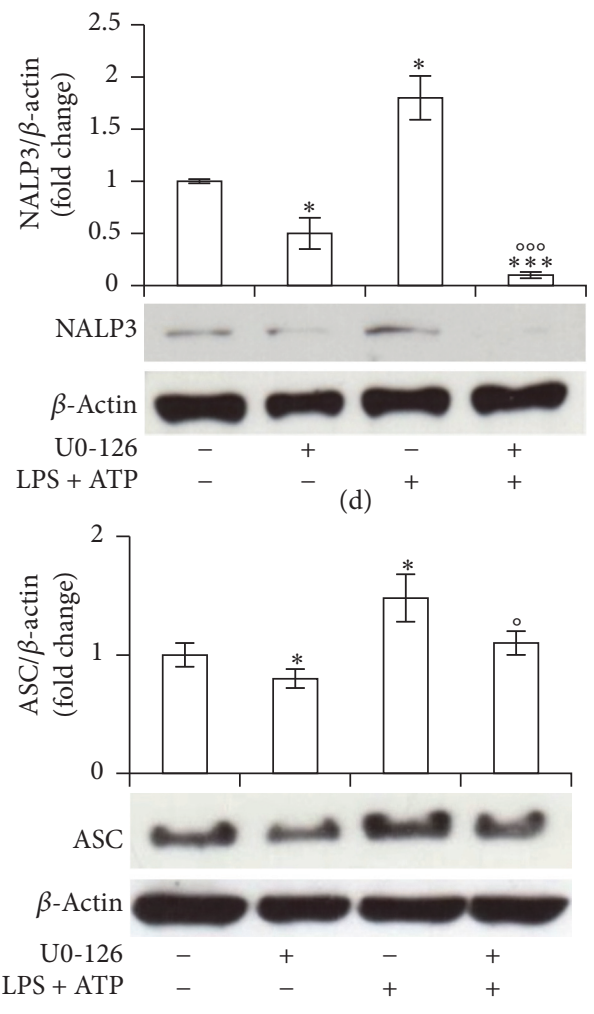

(e)

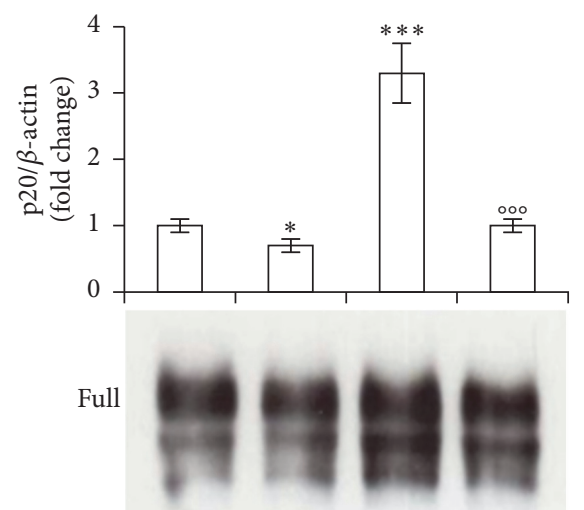

Caspase-1

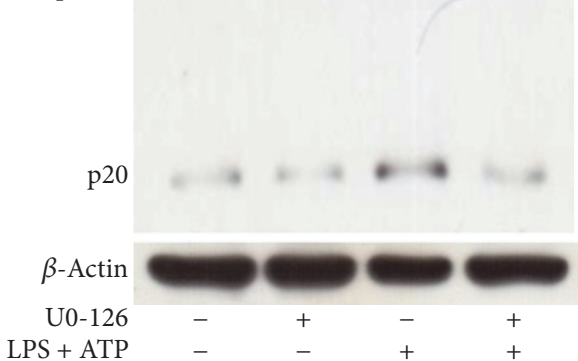

(f)

FIGURE 5: NF-kB and ERK 1/2 are involved in NALP3/ASC/Caspase-1 cascade activation in THP-1 cells. THP-1 cells were incubated with $10 \mu \mathrm{M}$ BAY 11-7082 (a, b, c) or U0-126 (d, e, f) for $1 \mathrm{~h}$ and then treated with $10 \mu \mathrm{g} / \mathrm{mL}$ LPS $/ 5 \mathrm{mM}$ ATP for $30 \mathrm{~min}$. Cell lysates were immunoblotted for NALP3 (a, d), ASC (b, e), or Caspase-1 (c, f). The blots were stripped of the bound Ab and reprobed with mouse anti- $\beta$-actin, to confirm equal loading. Western blots are representative of three separate experiments. Histograms indicate means \pm SD of three separate experiments each one tested in triplicate. ${ }^{*} P<0.05,{ }^{* *} P<0.01$, and ${ }^{* * *} P<0.001$ versus untreated cells and ${ }^{\circ} P<0.05,{ }^{\circ} P<0.01$, and ${ }^{\circ 00} P<0.001$ versus LPS/ATP treated cells. 


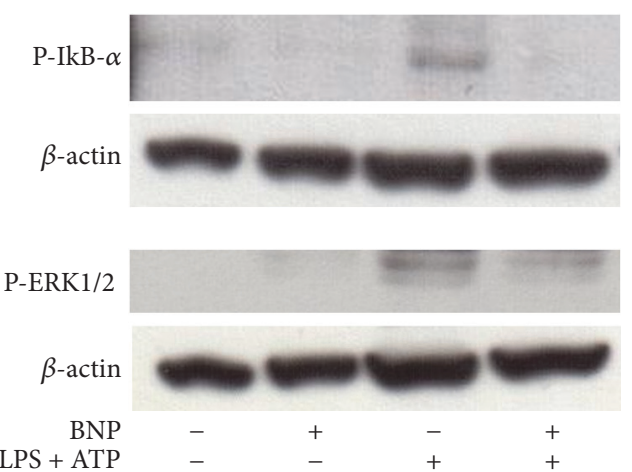

(a)
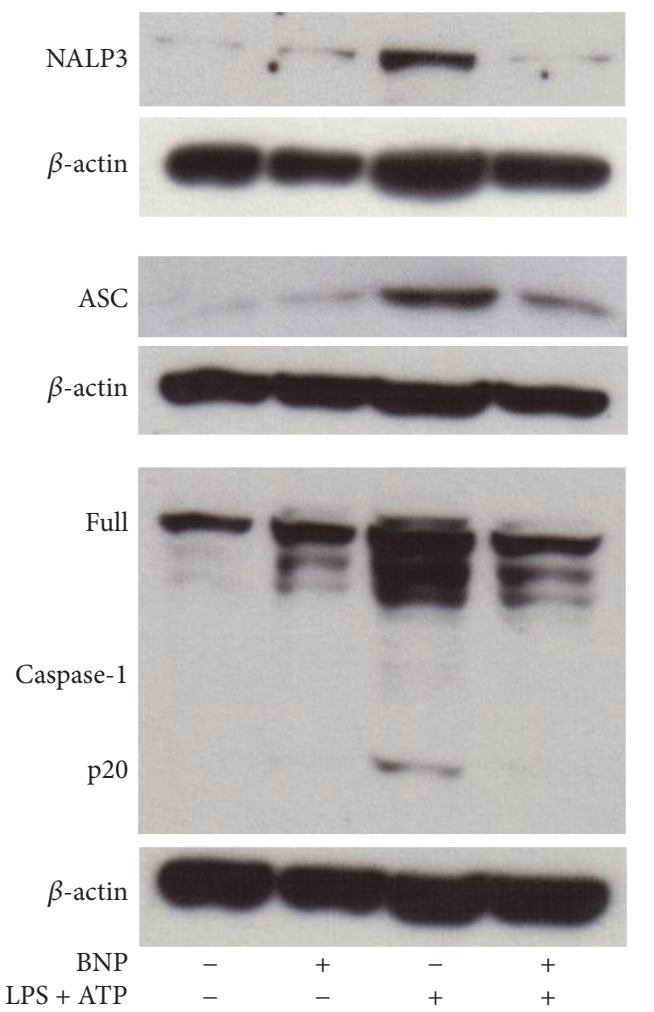

(b)

FIGURE 6: BNP is involved all the molecular mechanisms controlling IL- $1 \beta$ production and release by inhibiting the activation of NF-kB, ERK $1 / 2$ and of all the elements of NALP3 inflammasome/ASC/Caspase-1 cascade in macrophage-like cells. PMA differentiated THP-1 cells were treated with $10^{-8} \mathrm{M}$ BNP in absence or presence of $10 \mu \mathrm{g} / \mathrm{mL}$ LPS $/ 5 \mathrm{mM}$ ATP for $30 \mathrm{~min}$. Cell lysates were immunoblotted for P-IkB- $\alpha$ and P-ERK1/2 (a) or NALP3, ASC, or Caspase-1 (b). The blots were stripped of the bound $\mathrm{Ab}$ and reprobed with mouse anti- $\beta$-actin, to confirm equal loading. Western blots are representative of three separate experiments.

is particularly important. Moreover, these data support the anti-inflammatory and immunomodulatory role of BNP on human monocytes.

Our results, in line with BNP modulatory effect on other inflammatory mediators [36], suggest that during inflammation, where a complex network of pleiotropic mediators from plasma or cells (including monocytes and macrophages) occurs, BNP, by inhibiting IL-1 $\beta$ secretion, can affect the injured tissues-related inflammatory reactions, contributing to restoring cytokines production balance. In fact, since IL-1 $\beta$ stimulates the production and release of additional cytokines, BNP, by inhibiting it, can play an important compensatory role. Besides, in conditions where IL-1 $\beta$ and other cytokines levels are increased, such as after myocardial infraction and during progression of heart failure [42], elevated BNP plasma levels have been found [43]. Moreover, BNP levels increase also in patients during inflammatory contexts such as severe sepsis or septic shock [37,39], and in several inflammatory pathologies with or without cardiac dysfunction [37]. Since IL-1 $\beta$ is a strong regulator of BNP promoter [29], we suggest that the observed BNP increase during IL-1 $\beta$-related inflammatory contexts might be due to the direct effect of this cytokine. Concomitantly, the here found BNP inhibition of IL- $1 \beta$ release might contribute also to balance and/or restore BNP secretion itself, by an autocrine/paracrine loop. In support, NPR-1 is expressed on human monocytes $[35,38]$, macrophages [44], monocyte-derived dendritic cells [45], and peripheral blood mononuclear cells [35]. In agreement, here we newly report that THP-1 cells respond to BNP with an increase in cGMP production, thus indicating NPR-1 activation. Therefore, we suggest that in human monocytes, by inhibiting IL- $1 \beta$, the BNP/NPR-1/cGMP axis has an immune-regulatory and anti-inflammatory role. In addition, we suggest that $\mathrm{BNP}$ might exert these actions also in tissue microenvironment, where BNP autocrine/paracrine mechanisms may occur [31]. This appears to be of special interest also in the pathogenesis of cardiovascular diseases, including hypertrophy, myocardial infraction, and heart failure, where the inflammatory response takes place and BNP release is particularly elevated [31-33]. Analyzing the molecular mechanism of BNP inhibitory action on IL- $1 \beta$ secretion, we firstly demonstrated the involvement of NF-kB and ERK1/2 pathways in our system, their inhibitors being able to strongly downregulate LPS/ATP-induced pro- and IL-1 $\beta$ production. Subsequently, we demonstrated BNP's capability to inhibit both these pathways and pro-IL-1 $\beta$ protein expression. The observed BNP inhibitory action on NF-kB and ERK 1/2 activation in human monocytes has been confirmed also in macrophages-like cells, in agreement with similar results obtained in animal models $[47,48]$. Regarding NF-kB, we demonstrated that BNP inhibited IkB- $\alpha$ phosphorylation, essential for the release of the active form of this transcription factor [15]. Even though we did not investigate BNP inhibitory mechanism on NF-kB and ERK $1 / 2$ activation, we hypothesize that this might be related to multiple processes. For instance, BNP inhibition of IkB- $\alpha$ phosphorylation could be the result of an indirect mechanism, occurring via BNPinduced ERK1/2 downregulation, this latter being a pathway involved in NF-kB activation by IkB- $\alpha$ phosphorylation [18]. Interestingly, the here observed BNP inhibition of IkB- $\alpha$ phosphorylation could be implicated also in the inhibitory effect of BNP on ERK 1/2, being IKK family involved in both NF-kB and ERK1/2 activation [17]. In addition, BNP-induced ERK 1/2 inhibition might be ascribed also to the here found BNP-induced increase in cGMP levels. In fact, both increased 


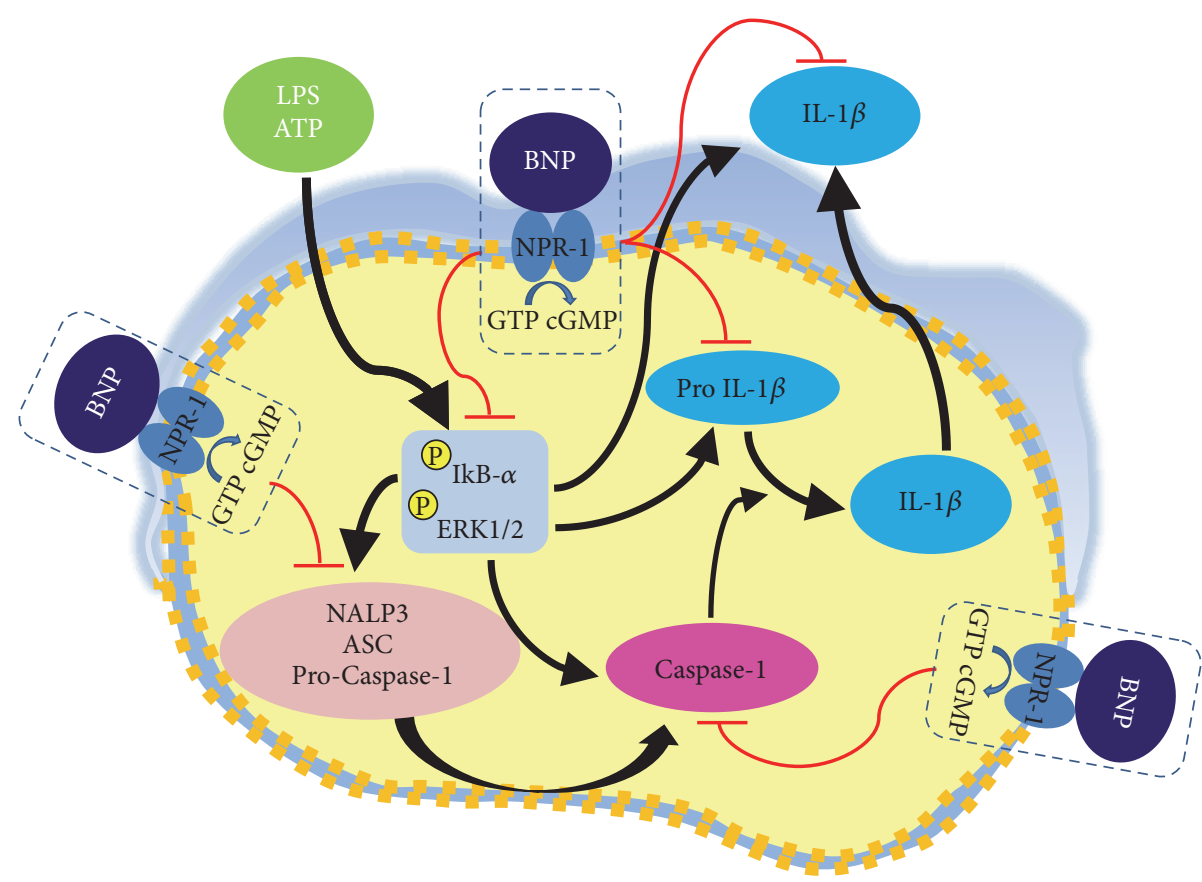

FIGURE 7: Mechanism of action of BNP inhibitory effect on LPS/ATP-induced IL-1 $\beta$ secretion in human THP-1 monocyte. BNP/NPR1/cGMP axis strongly inhibits IL- $1 \beta$ secretion by acting both at transcriptional and at posttranslational level. Firstly, by inhibiting the activation of NF$\mathrm{kB}$ and ERK $1 / 2$ signaling pathway, BNP downregulates the production of the inactive cytoplasmic precursor pro-IL-1 $\beta$. Subsequently, again by inhibiting NF-kB and ERK 1/2 activation, BNP strongly downregulates all the elements of NALP3 inflammasome/ASC/Caspase-1 cascade and Caspase -1 activation, essential steps for the formation of the active secreted IL- $1 \beta$ protein.

cGMP levels [49] or cGMP-dependent kinases exert a direct downregulation of ERK $1 / 2$ activation [50]. In addition, we do not exclude that both NF-kB or ERK 1/2 inhibitions may be the result of a negative feed-back loop via IL- $1 \beta$, this cytokine being an activator of both these pathways $[1,15]$. Finally, such inhibitions could be related to the here observed downregulatory effect of BNP on ASC expression, ASC itself being an important activator of both these pathways [2, 28]. The biological relevance of BNP-induced NF-kB/ERK1/2 inhibitions is that BNP may exert an anti-inflammatory and immunomodulatory role via the regulation of such pathways. In fact, both these signaling are involved in LPS-induced proinflammatory responses and their activation result in a rapid release of proinflammatory cytokines into the circulation, leading to an additional inflammatory response $[15,46]$. In addition, it has been demonstrated in mouse macrophages that NF-kB activation additionally turns on NALP3 transcription, thereby licensing NALP3 inflammasome activation $[6,51]$. Therefore, we suggest that BNP inhibitory effect on NF-kB and ERK $1 / 2$ can be further investigated for a potential therapeutic employment of this hormone in the treatment of inflammatory diseases, where the application of chemical NF-kB and ERK 1/2 inhibitors may cause problems related to their efficacy and side effects $[52,53]$. Besides, BNP infusion is used on top of standard care, providing clinical benefit in acutely decompensated heart failure patients $[54,55]$. Regarding the second part of the mechanism controlling IL-1 $\beta$ secretion, we showed that BNP completely reverted LPS/ATP-induced NALP3, ASC and pro-Caspase-1 protein expression and NALP3 inflammasome activation both in monocytes and in macrophage-like cells. BNP capability to downregulate NALP3/ASC/Caspase-1 protein expression demonstrates its involvement in the priming/licensing step of inflammasome activation in these different cellular systems and represents an important new mechanism of action for this natriuretic peptide. In addition, we demonstrated that BNP completely blocked LPS/ATP-induced Caspase-1 active fragment production, both in THP-1 monocyte and in macrophage-like cells. Since the hallmark of NALP3 inflammasome activation is the proteolytic cleavage of Caspase1 that, in turn, cleaves pro-IL- $1 \beta$ into the mature form IL- $1 \beta$, our results indicate BNP involvement also in the second mechanism of inflammasome activation. This effect appears to be particularly important since NALP3 inflammasome components may have roles also in inflammasomeindependent cytokine production and noninflammasomerelated cytokines can influence the activation of the inflammasome [6]. Therefore, we suggest that BNP may exert anti-inflammatory and immunomodulatory effect also via the downregulation of both the elements of this molecular platform and its activation, implicated in the pathogenesis of major human diseases with a high prevalence worldwide [1, 4-11, 19-27]. Hence, BNP could be further investigated also for its potential therapeutic effect on NALP3/ASC/Caspase1 associated disorders also in consideration of the fact that many of the autoimmune diseases are refractory to most therapies and that immunosuppressive agents have many side effects [6]. Analyzing the mechanism of action of 
BNP inhibitory effect on NALP3/ASC/Caspase-1 cascade, we finally demonstrated that it is directly related to BNP deregulatory effect on NF-kB and ERK $1 / 2$ activation. In fact, the specific BAY 11-7082 and U0-126 inhibitors completely reverted LPS/ATP-induced NALP3, ASC, and Caspase-1 protein expression and Caspase-1 activation. These results are in agreement with previous data demonstrating that NALP3 expression is dependent on NF-kB activation $[4,51]$ and that BAY 11-7082 is able to inhibit both NALP3 inflammasome and Caspase-1 activation in a murine model [56]. Moreover, it has been recently demonstrated that NALP3 inflammasome activation by LPS requires ERK $1 / 2$ and that U0-126 significantly blocks it [46].

\section{Conclusions}

In conclusion, we demonstrated a novel role for BNP/NPR$1 /$ cGMP axis: downregulation of IL-1 $\beta$ secretion from THP1 monocytes, via a strong inhibition of all the molecular mechanisms controlling its production and secretion: NF$\mathrm{kB}$, ERK 1/2, and NALP3/ASC/Caspase-1 cascade. Regarding BNP inhibitory effect on NALP3 inflammasome activation, we demonstrated that it is related to BNP-induced downregulation of NF-kB and ERK 1/2 activation.

Our data point out a potent anti-inflammatory and immunomodulatory role for this peptide suggesting a possible employment of this endogenous agent, already used for the treatment of heart failure $[54,55]$, also in the treatment of inflammatory/immune-related and IL- $1 \beta / \mathrm{NF}-\mathrm{kB} /$ ERK1/2/NALP3/ASC/Caspase-1-associated diseases, known to affect millions of people worldwide.

\section{Disclosure}

The authors state that some data of the present work were presented at the conference: "XVII Congresso Nazionale AIBG (Cagliari, September 30th/October 1st, 2016)”.

\section{Competing Interests}

The authors declare that there is no conflict of interests regarding the publication of this study.

\section{Acknowledgments}

This work was supported by Fondazione Cassa di Risparmio di Perugia (COD. 2014.0257.021). The authors thank Mr. Francesco Fabi for the technical assistance.

\section{References}

[1] C. A. Dinarello, "Immunological and inflammatory functions of the interleukin-1 family," Annual Review of Immunology, vol. 27, pp. 519-550, 2009.

[2] B. R. Barker, D. J. Taxman, and J. P.-Y. Ting, "Cross-regulation between the IL-1 $\beta / \mathrm{IL}-18$ processing inflammasome and other inflammatory cytokines," Current Opinion in Immunology, vol. 23 , no. 5, pp. 591-597, 2011.
[3] F. Martinon, A. Mayor, and J. Tschopp, "The inflammasomes: guardians of the body," Annual Review of Immunology, vol. 27, pp. 229-265, 2009.

[4] P. Menu and J. E. Vince, "The NLRP3 inflammasome in health and disease: the good, the bad and the ugly," Clinical and Experimental Immunology, vol. 166, no. 1, pp. 1-15, 2011.

[5] B. K. Davis, H. Wen, and J. P.-Y. Ting, "The inflammasome NLRs in immunity, inflammation, and associated diseases," Annual Review of Immunology, vol. 29, pp. 707-735, 2011.

[6] C. Bryant and K. A. Fitzgerald, "Molecular mechanisms involved in inflammasome activation," Trends in Cell Biology, vol. 19, no. 9, pp. 455-464, 2009.

[7] I. C. Allen, M. A. Scull, C. B. Moore et al., "The NLRP3 inflammasome mediates in vivo innate immunity to influenza a virus through recognition of viral RNA," Immunity, vol. 30, no. 4, pp. 556-565, 2009.

[8] S. Chakraborty, D. K. Kaushik, M. Gupta, and A. Basu, "Inflammasome signaling at the heart of central nervous system pathology," Journal of Neuroscience Research, vol. 88, no. 8, pp. 1615-1631, 2010.

[9] M. Daheshia and J. Q. Yao, "The interleukin $1 \beta$ pathway in the pathogenesis of osteoarthritis," Journal of Rheumatology, vol. 35, no. 12, pp. 2306-2312, 2008.

[10] Y. Dombrowski, M. Peric, S. Koglin et al., "Cytosolic DNA triggers inflammasome activation in keratinocytes in psoriatic lesions," Science Translational Medicine, vol. 3, no. 82, Article ID 82ra38, 2011.

[11] C. M. Artlett, "Inflammasomes in wound healing and fibrosis," Journal of Pathology, vol. 229, no. 2, pp. 157-167, 2013.

[12] N. A. Thornberry, H. G. Bull, J. R. Calaycay et al., "A novel heterodimeric cysteine protease is required for interleukin$1 \beta$ processing in monocytes," Nature, vol. 356 , no. 6372, pp. $768-$ 774, 1992.

[13] S. Papoutsopoulou, A. Symons, T. Tharmalingham et al., "ABIN2 is required for optimal activation of Erk MAP kinase in innate immune responses," Nature Immunology, vol. 7, no. 6, pp. 606$615,2006$.

[14] E. Jo, J. K. Kim, D. Shin, and C. Sasakawa, "Molecular mechanisms regulating NLRP3 inflammasome activation," Cellular and Molecular Immunology, vol. 13, no. 2, pp. 148-159, 2015.

[15] B. Hoesel and J. A. Schmid, "The complexity of NF- $\kappa$ B signaling in inflammation and cancer," Molecular Cancer, vol. 12, article 86, 2013.

[16] P. P. Roux and J. Blenis, "ERK and p38 MAPK-activated protein kinases: a family of protein kinases with diverse biological functions," Microbiology and Molecular Biology Reviews, vol. 68, no. 2, pp. 320-344, 2004.

[17] T. Gantke, S. Sriskantharajah, M. Sadowski, and S. C. Ley, "I $\kappa$ B kinase regulation of the TPL-2/ERK MAPK pathway," Immunological Reviews, vol. 246, no. 1, pp. 168-182, 2012.

[18] J. A. McCubrey, L. S. Steelman, W. H. Chappell et al., "Roles of the Raf/MEK/ERK pathway in cell growth, malignant transformation and drug resistance," Biochimica et Biophysica ActaMolecular Cell Research, vol. 1773, no. 8, pp. 1263-1284, 2007.

[19] F. Martinon, V. Pétrilli, A. Mayor, A. Tardivel, and J. Tschopp, "Gout-associated uric acid crystals activate the NALP3 inflammasome," Nature, vol. 440, no. 7081, pp. 237-241, 2006.

[20] R. W. Grant and V. D. Dixit, "Mechanisms of disease: inflammasome activation and the development of type 2 diabetes," Frontiers in Immunology, vol. 4, article 50, 2013. 
[21] R. Stienstra, J. A. Van Diepen, C. J. Tack et al., "Inflammasome is a central player in the induction of obesity and insulin resistance," Proceedings of the National Academy of Sciences of the United States of America, vol. 108, no. 37, pp. 15324-15329, 2011.

[22] A.-C. Villani, M. Lemire, G. Fortin et al., "Common variants in the NLRP3 region contribute to Crohn's disease susceptibility," Nature Genetics, vol. 41, pp. 71-76, 2009.

[23] V. Hornung, F. Bauernfeind, A. Halle et al., "Silica crystals and aluminum salts activate the NALP3 inflammasome through phagosomal destabilization," Nature Immunology, vol. 9, no. 8, pp. 847-856, 2008.

[24] M. Okamoto, W. Liu, Y. Luo et al., "Constitutively active inflammasome in human melanoma cells mediating autoinflammation via caspase-1 processing and secretion of interleukin-1 $\beta$," Journal of Biological Chemistry, vol. 285, no. 9, pp. 6477-6488, 2010.

[25] A. Halle, V. Hornung, G. C. Petzold et al., "The NALP3 inflammasome is involved in the innate immune response to amyloid- $\beta$," Nature Immunology, vol. 9, no. 8, pp. 857-865, 2008.

[26] M. T.-H. Huang, D. J. Taxman, E. A. Holley-Guthrie et al., "Critical role of apoptotic speck protein containing a caspase recruitment domain (ASC) and NLRP3 in causing necrosis and asc speck formation induced by Porphyromonas gingivalis in human cells," The Journal of Immunology, vol. 182, no. 4, pp. 2395-2404, 2009.

[27] S. K. Ippagunta, D. D. Brand, J. Luo et al., "Inflammasomeindependent role of apoptosis-associated speck-like protein containing a CARD (ASC) in T cell priming is critical for collagen-induced arthritis," Journal of Biological Chemistry, vol. 285, no. 16, pp. 12454-12462, 2010.

[28] D. J. Taxman, E. A. Holley-Guthrie, M. Tze-Han Huang et al., "The NLR adaptor ASC/PYCARD regulates DUSP10, mitogenactivated protein kinase (MAPK), and chemokine induction independent of the inflammasome," Journal of Biological Chemistry, vol. 286, no. 22, pp. 19605-19616, 2011.

[29] Q. He and M. C. LaPointe, "Interleukin- $1 \beta$ regulates the human brain natriuretic peptide promoter via $\mathrm{Ca}^{2+}$-dependent protein kinase pathways," Hypertension, vol. 35, no. 1, pp. 292-296, 2000.

[30] L. R. Potter, A. R. Yoder, D. R. Flora, L. K. Antos, and D. M. Dickey, "Natriuretic peptides: their structures, receptors, physiologic functions and therapeutic applications," in cGMP: Generators, Effectors and Therapeutic Implications, vol. 191 of Handbook of Experimental Pharmacology, pp. 341-366, Springer, 2009.

[31] S. P. D'Souza, M. Davis, and G. F. Baxter, "Autocrine and paracrine actions of natriuretic peptides in the heart," Pharmacology and Therapeutics, vol. 101, no. 2, pp. 113-129, 2004.

[32] N. Hama, H. Itoh, G. Shirakami et al., "Rapid ventricular induction of brain natriuretic peptide gene expression in experimental acute myocardial infarction," Circulation, vol. 92, no. 6, pp. 1558-1564, 1995.

[33] O. Nakagawa, Y. Ogawa, H. Itoh et al., "Rapid transcriptional activation and early mRNA turnover of brain natriuretic peptide in cardiocyte hypertrophy. evidence for brain natriuretic peptide as an 'emergency' cardiac hormone against ventricular overload," Journal of Clinical Investigation, vol. 96, no. 3, pp. 1280-1287, 1995.

[34] K. N. Pandey, "Guanylyl cyclase/natriuretic peptide receptorA signaling antagonizes phosphoinositide hydrolysis, $\mathrm{Ca}^{2+}$ release, and activation of protein kinase C," Frontiers in Molecular Neuroscience, vol. 7, article 75, 2014.
[35] N. Glezeva, P. Collier, V. Voon et al., "Attenuation of monocyte chemotaxis-a novel anti-inflammatory mechanism of action for the cardio-protective hormone B-type natriuretic peptide," Journal of Cardiovascular Translational Research, vol. 6, no. 4, pp. 545-557, 2013.

[36] V. Chiurchiù, V. Izzi, F. D’Aquilio, F. Carotenuto, P. Di Nardo, and P. M. Baldini, "Brain natriuretic peptide (BNP) regulates the production of inflammatory mediators in human THP-1 macrophages," Regulatory Peptides, vol. 148, no. 1-3, pp. 26-32, 2008.

[37] T. Ogawa and A. J. de Bold, "Brain natriuretic peptide production and secretion in inflammation," Journal of Transplantation, vol. 2012, Article ID 962347, 7 pages, 2012.

[38] L. Mezzasoma, C. Antognelli, and V. N. Talesa, "Atrial natriuretic peptide down-regulates LPS/ATP-mediated IL- $1 \beta$ release by inhibiting NF-kB, NLRP3 inflammasome and caspase-1 activation in THP-1 cells," Immunologic Research, vol. 64, no. 1, pp. 303-312, 2016.

[39] A. Rudiger, S. Gasser, M. Fischler, T. Hornemann, A. Von Eckardstein, and M. Maggiorini, "Comparable increase of Btype natriuretic peptide and amino-terminal pro-B-type natriuretic peptide levels in patients with severe sepsis, septic shock, and acute heart failure," Critical Care Medicine, vol. 34 , no. 8 , pp. 2140-2144, 2006.

[40] K. K. Ma, T. Ogawa, and A. J. de Bold, "Selective upregulation of cardiac brain natriuretic peptide at the transcriptional and translational levels by pro-inflammatory cytokines and by conditioned medium derived from mixed lymphocyte reactions via p38 MAP kinase," Journal of Molecular and Cellular Cardiology, vol. 36, no. 4, pp. 505-513, 2004.

[41] L. Mezzasoma, L. Cagini, C. Antognelli, F. Puma, E. Pacifico, and V. N. Talesa, "TNF- $\alpha$ regulates natriuretic peptides and aquaporins in human bronchial epithelial cells BEAS-2B," Mediators of Inflammation, vol. 2013, Article ID 159349, 13 pages, 2013.

[42] M. Testa, M. Yeh, P. Lee et al., "Circulating levels of cytokines and their endogenous modulators in patients with mild to severe congestive heart failure due to coronary artery disease or hypertension," Journal of the American College of Cardiology, vol. 28, no. 4, pp. 964-971, 1996.

[43] T. Omland, A. Aakvaag, V. V. S. Bonarjee et al., "Plasma brain natriuretic peptide as an indicator of left ventricular systolic function and long-term survival after acute myocardial infarction: comparison with plasma atrial natriuretic peptide and N-terminal proatrial natriuretic peptide," Circulation, vol. 93, no. 11, pp. 1963-1969, 1996.

[44] P. M. Baldini, P. De Vito, A. Martino et al., "Differential sensitivity of human monocytes and macrophages to ANP: a role of intracellular $\mathrm{pH}$ on reactive oxygen species production through the phospholipase involvement," Journal of Leukocyte Biology, vol. 73, no. 4, pp. 502-510, 2003.

[45] R. Morita, N. Ukyo, M. Furuya, T. Uchiyama, and T. Hori, "Atrial natriuretic peptide polarizes human dendritic cells toward a Th2-promoting phenotype through its receptor guanylyl cyclase-coupled receptor A," The Journal of Immunology, vol. 170, no. 12, pp. 5869-5875, 2003.

[46] M. G. Ghonime, O. R. Shamaa, S. Das et al., "Inflammasome priming by lipopolysaccharide is dependent upon ERK signaling and proteasome function," Journal of Immunology, vol. 192, no. 8, pp. 3881-3888, 2014. 
[47] Y. Pan, W. Zhu, J. Ma et al., “Therapeutic effects of continuous infusion of brain natriuretic peptides on postmyocardial infarction ventricular remodelling in rats," Archives of Cardiovascular Diseases, vol. 104, no. 1, pp. 17-28, 2011.

[48] T. Suganami, M. Mukoyama, A. Sugawara et al., "Overexpression of brain natriuretic peptide in mice ameliorates immunemediated renal injury," Journal of the American Society of Nephrology, vol. 12, no. 12, pp. 2652-2663, 2001.

[49] A. J. Ingram, L. James, L. Cai, K. Thai, H. Ly, and J. W. Scholey, "NO inhibits stretch-induced MAPK activity by cytoskeletal disruption," Journal of Biological Chemistry, vol. 275, no. 51, pp. 40301-40306, 2000.

[50] M. Suhasini, H. Li, S. M. Lohmann, G. R. Boss, and R. B. Pilz, "Cyclic-GMP-dependent protein kinase inhibits the Ras/mitogen-activated protein kinase pathway," Molecular and Cellular Biology, vol. 18, no. 12, pp. 6983-6994, 1998.

[51] F. G. Bauernfeind, G. Horvath, A. Stutz et al., "Cutting edge: NF- $\kappa \mathrm{B}$ activating pattern recognition and cytokine receptors license NLRP3 inflammasome activation by regulating NLRP3 expression," The Journal of Immunology, vol. 183, no. 2, pp. 787791, 2009.

[52] B. Zingarelli, M. Sheehan, and H. R. Wong, "Nuclear factor- $\kappa$ B as a therapeutic target in critical care medicine," Critical Care Medicine, vol. 31, no. 1, pp. S105-S111, 2003.

[53] D. E. Uehling and P. A. Harris, "Recent progress on MAP kinase pathway inhibitors," Bioorganic and Medicinal Chemistry Letters, vol. 25, no. 19, pp. 4047-4056, 2015.

[54] A.S. Maisel, "Nesiritide: a new therapy for the treatment of heart failure," Cardiovascular Toxicology, vol. 3, no. 1, pp. 37-42, 2003.

[55] G. F. Schreiner and A. A. Protter, "B-type natriuretic peptide for the treatment of congestive heart failure," Current Opinion in Pharmacology, vol. 2, no. 2, pp. 142-147, 2002.

[56] J. Zhao, H. Zhang, Y. Huang et al., "Bayll-7082 attenuates murine lupus nephritis via inhibiting NLRP3 inflammasome and NF- $\kappa \mathrm{B}$ activation," International Immunopharmacology, vol. 17, no. 1, pp. 116-122, 2013. 


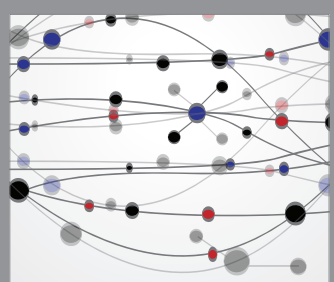

The Scientific World Journal
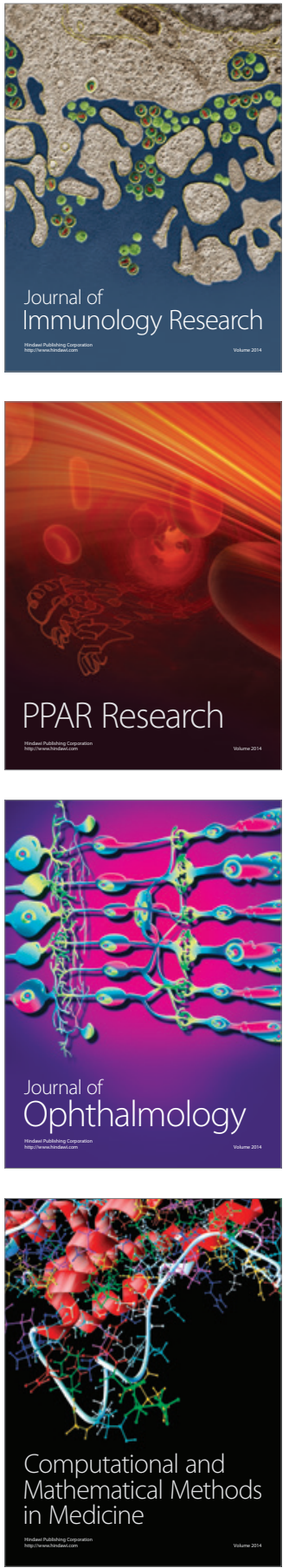

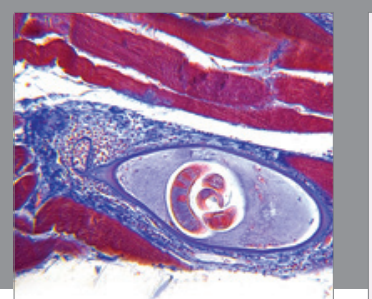

Gastroenterology Research and Practice
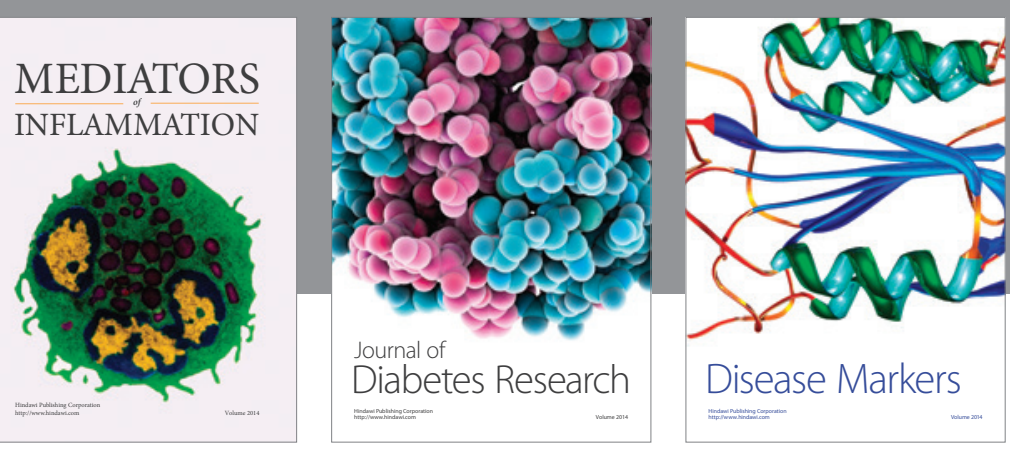

Disease Markers

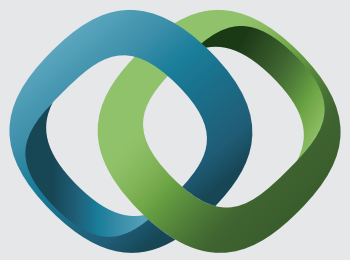

\section{Hindawi}

Submit your manuscripts at

https://www.hindawi.com
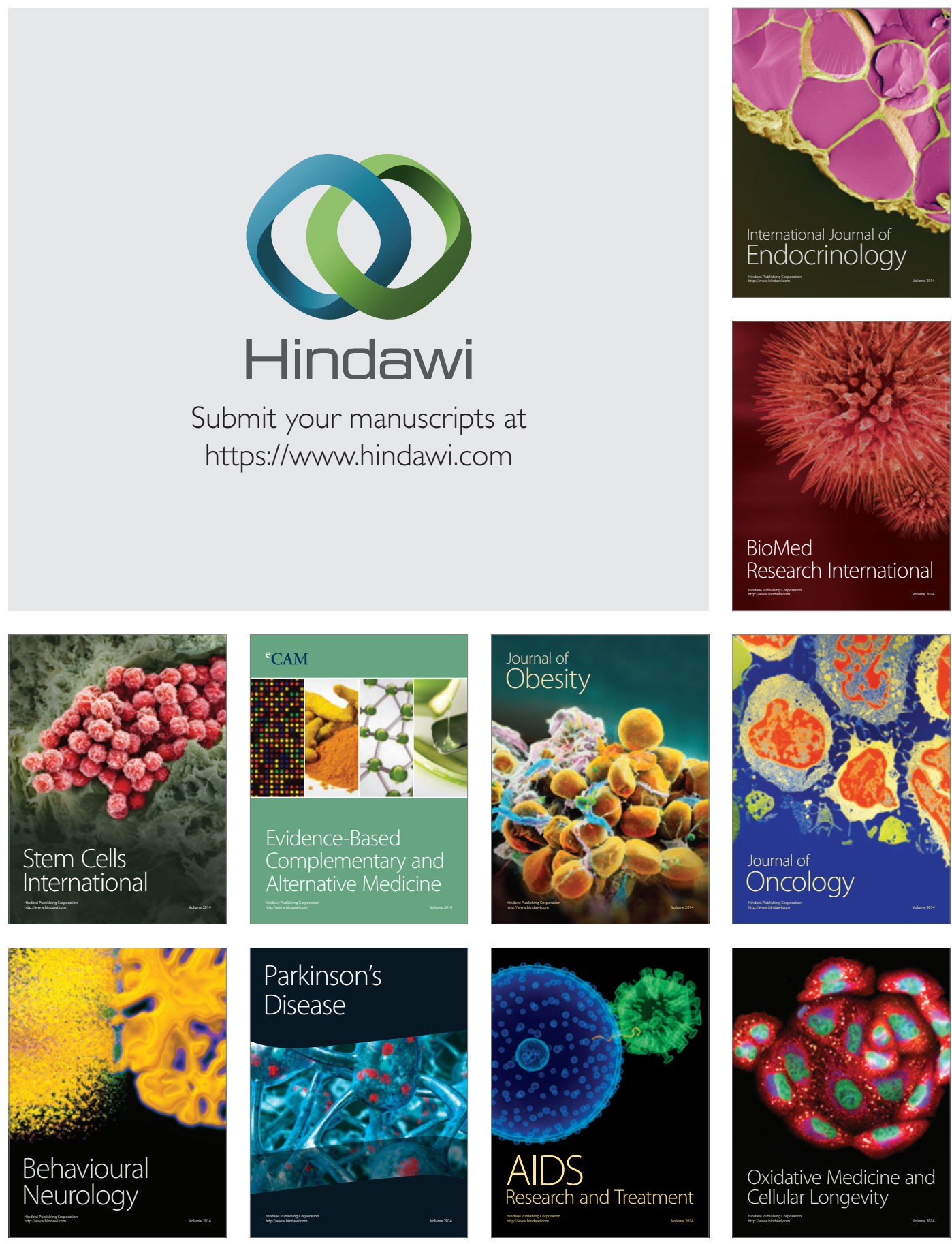